\title{
Contrasting insulin dose-dependent defects in activation of atypical protein kinase $C$ and protein kinase B/Akt in muscles of obese diabetic humans
}

\author{
L. Casaubon • M. P. Sajan • J. Rivas • J. L. Powe • \\ M. L. Standaert $\cdot$ R. V. Farese
}

Received: 7 December 2005 / Accepted: 18 July 2006 / Published online: 7 October 2006

(C) Springer-Verlag 2006

\begin{abstract}
Aims/hypothesis Insulin-stimulated glucose transport in muscle is impaired in obesity and type 2 diabetes, but alterations in levels of relevant signalling factors, i.e. atypical protein kinase $\mathrm{C}(\mathrm{aPKC})$ and protein kinase $\mathrm{B}$ (PKB/Akt), are still uncertain. Clamp studies using maximal insulin concentrations have revealed defects in activation of aPKC, but not PKB, in both obese non-diabetic and obese diabetic subjects. In contrast, clamp studies using submaximal insulin concentrations revealed defects in PKB activation/phosphorylation in obese non-diabetic and diabetic subjects, but changes in aPKC were not reported. The aim of this study was to test the hypothesis that dose-related effects of insulin may account for the reported differences in insulin signalling to PKB in diabetic muscle.

Subjects and methods We compared enzymatic activation of aPKC and PKB, and PKB phosphorylation (threonine308 and serine-473) during hyperinsulinaemic-euglycaemic clamp studies using both submaximal (400-500 pmol/l) and maximal (1400 pmol/l) insulin levels in non-diabetic control and obese diabetic subjects.

Results In lean control subjects, the submaximal insulin concentration increased aPKC activity and glucose disposal to approximately $50 \%$ of the maximal level and $\mathrm{PKB} \beta$ activity to $25 \%$ of the maximal level, but $\mathrm{PKB} \alpha$ activity was not increased. In these subjects, phosphorylation of $\mathrm{PKB} \alpha$ and $\mathrm{PKB} \beta$ was increased to near-maximal levels at
\end{abstract}

L. Casaubon · M. P. Sajan · J. Rivas · J. L. Powe

M. L. Standaert $\cdot$ R. V. Farese $(\bowtie)$

Research Service, James A. Haley Veterans Administration

Medical Center and Department of Internal Medicine,

University of South Florida College of Medicine,

Tampa, FL, USA

e-mail: rfarese@hsc.usf.edu submaximal insulin concentrations. In obese diabetic subjects, whereas aPKC activation was defective at submaximal and maximal insulin concentrations, $\mathrm{PKB} \beta$ activation and the phosphorylation of $\mathrm{PKB} \beta$ and $\mathrm{PKB} \alpha$ were defective at submaximal, but not maximal, insulin concentrations.

Conclusions/interpretations Defective PKB $\beta$ activation/ phosphorylation, seen on submaximal insulin stimulation in diabetic muscle, may largely reflect impaired activation of insulin signalling factors present in concentrations greater than those needed for full PKB activation/phosphorylation. Defective aPKC activation, seen at all insulin levels, appears to reflect, at least partly, an impaired action of distal factors needed for aPKC activation, or poor aPKC responsiveness.

Keywords Atypical protein kinase C · Diabetes · Insulin . Insulin resistance $\cdot$ Muscle $\cdot$ Protein kinase B .

Protein kinase $\mathrm{C}-\zeta$
Abbreviations
aPKC atypical protein kinase $\mathrm{C}$
PI3K phosphatidylinositol 3-kinase
PIP3 phosphatidylinositol-3,4,5-trisphosphate
PDK1 3-phosphoinositide-dependent protein kinase-1
PDK2 3-phosphoinositide-dependent protein kinase-2
$\mathrm{PKB}$ protein kinase $\mathrm{B}$

\section{Introduction}

Skeletal muscle insulin resistance is present throughout a spectrum of inter-related disorders ranging from obesity and the metabolic syndrome to type 2 diabetes mellitus. Insulin resistance in skeletal muscle in both obesity and 
type 2 diabetes is due to diminished ability of insulin to stimulate glucose transport and the subsequent utilisation of glucose in glycolytic and glycogen storage pathways.

Insulin-stimulated glucose transport, the initial, presumably rate-limiting step for muscle glucose metabolism, requires the activation of IRS1-dependent phosphatidylinositol 3-kinase (PI3K), followed by activation of atypical protein kinase $\mathrm{C}(\mathrm{aPKC})$ [1-10] and protein kinase $\mathrm{B}$ (PKB/Akt) [8-15]. Both post-PI3K signalling factors participate in stimulating the translocation of glucose transporter GLUT4 to the plasma membrane, thereby facilitating glucose entry.

Defective activation of IRS1-dependent PI3K in muscles of obese [16] and type 2 diabetic subjects [17] seems clear. Findings in certain euglycaemic-hyperinsulinaemic clamp studies, designed to examine defects in the activation of post-PI3K signalling factors at maximal insulin stimulation, have shown that the enzymatic activation of aPKC, as well as of IRS1-dependent PI3K, is impaired in muscles of obese diabetic $[18,19]$ and obese non-diabetic $[18,20]$ humans; however, significant defects in PKB enzymatic activation and/or phosphorylation were not evident in these clamp studies [18-21]. On the other hand, defects in PKB activation or phosphorylation have been observed in incubations of isolated muscles of obese subjects [22] and non-obese type 2 diabetic subjects [23], and in muscles of obese non-diabetic [24] and diabetic [25] subjects studied in clamp procedures using submaximal insulin concentrations; unfortunately, aPKC activation was not examined in these studies [22-25]. Moreover, there are no studies in which the activation of either $\mathrm{APKC}$ or PKB was examined at both submaximal and maximal insulin concentrations.

Here, we asked whether some clamp studies may have failed to uncover defects in PKB activation/phosphorylation in muscles of obese or type 2 diabetic subjects because the insulin concentrations used were maximal rather than submaximal; such studies would have addressed the question of maximal responsiveness to insulin, rather than sensitivity. Accordingly, we conducted clamp studies in lean control subjects and obese subjects with type 2 diabetes using both submaximal (approximately half-maximal for glucose disposal) and maximal or near-maximal insulin concentrations. Interestingly, in muscles of lean control subjects, phosphorylation of $\mathrm{PKB} \alpha$ and $\mathrm{PKB} \beta$ (reflecting activation by upstream signalling factors) approached a maximum at an insulin level considerably less than that required for full activation of $\mathrm{PKB} \beta$, aPKC and glucose disposal. Moreover, in obese diabetics, whereas defects in muscle aPKC activation were readily evident at both submaximal and maximal insulin concentrations, defective enzymatic activation and phosphorylation of $\mathrm{PKB} \beta$ was evident at submaximal, but not maximal, insulin levels.

\section{Subjects and methods}

Subjects We studied seven obese subjects with type 2 diabetes (five male and two female) (as reported previously $[18,20]$ and confirmed in the present study, results of aPKC and $\mathrm{PKB}$ activation in males and females are indistinguishable and are therefore considered together in the present study), who were free of cardiovascular, renal, neuropathic and other significant medical problems. Diabetic medications (sulfonylurea or sulfonylurea plus metformin) were discontinued 3-4 weeks prior to the clamp/biopsy study, which was conducted with a submaximal level of insulin administration, and 1-2 weeks later, with a maximally effective level of insulin administration. Eight non-diabetic males were subjected to clamp/biopsy procedures identical to those performed in obese diabetic subjects, in order to provide control samples for side-by-side analyses and comparisons with samples from diabetic subjects. We did not include an obese non-diabetic group in the present study because (1) in previous high-dose clamp studies, obese-non-diabetic subjects and obese diabetic subjects were found to have similar qualitative alterations in $\mathrm{APKC}$ (decreased) and PKB (not significantly decreased) activation, the only difference being quantitative [18-20]; (2) defects in aPKC activation do not appear to be correlated with hyperglycaemia, and may be more reflective of obesity [18-20]; and (3) the purpose of the present study was to determine reasons for previous differences in findings and to further elucidate mechanisms for the defective activation of aPKC and PKB in the most severely affected obese diabetic subjects.

Six of the seven diabetic subjects and seven of eight non-diabetic subjects were studied using both maximal and submaximal insulin concentrations. All assays and comparisons were conducted with samples from both non-diabetic and diabetic subjects, studied using both submaximal and maximal insulin stimulation levels. Moreover, in all assays, each diabetic subject was compared with at least three nondiabetic control subjects to be certain that observed differences reflected true deviations from non-diabetic control subjects rather than random variations.

Informed consent was obtained from each participant before they entered the study. All procedures were reviewed, approved and monitored by the Institutional Review Board of the University of South Florida College of Medicine and the Research and Development Committee of the James A. Haley Veterans Hospital. Studies were performed in accordance with the Declaration of Helsinki and Good Clinical Practice.

Clamp/biopsy studies Hyperinsulinaemic-euglycaemic clamp/muscle biopsy studies were conducted in the morning after an overnight fast, as described [18, 20]. In 
brief, while the subject was receiving physiological saline intravenously and after the biopsy site had been anaesthetised with $0.5 \%$ lidocaine (without epinephrine), the skin was incised and a percutaneous biopsy of the vastus lateralis muscle was performed with a 14 gauge biopsy needle. Insulin was then given intravenously, first in a priming dose (14 and $42 \mathrm{pmol} / \mathrm{kg}$ body weight per min, for submaximal and maximal insulin treatments respectively) over $10 \mathrm{~min}$, and then at a constant rate proportional to body weight to attain serum insulin concentrations of approximately $400-500 \mathrm{pmol} / 1$ (submaximally effective for insulin-stimulated glucose disposal) or $1400 \mathrm{pmol} / 1$ (maximally or near-maximally effective for insulin-stimulated glucose disposal). Plasma glucose levels were clamped at 5-6.1 $\mathrm{mmol} / 1$ (measured every $5 \mathrm{~min}$ ) by varying the rate of a $20 \%$ glucose infusion. The clamp was continued for 90 120 min to attain steady-state glucose levels, and a second biopsy was obtained at this point. Insulin-stimulated glucose disposal rates and insulin levels were determined during the resulting steady-state condition attained during the last $30 \mathrm{~min}$ of the clamp procedure, as described [18, 20]. Muscle samples were frozen rapidly in liquid $\mathrm{N}_{2}$ and stored at $-70^{\circ} \mathrm{C}$.

Muscle kinase analyses Muscle samples were homogenised (Polytron) in buffer containing $20 \mathrm{mmol} / 1$ Tris- $\mathrm{HCl}$ (pH 7.5), $50 \mathrm{mmol} / 1 \mathrm{sucrose}, 2 \mathrm{mmol} / \mathrm{l} \mathrm{EDTA}, 2 \mathrm{~mol} / \mathrm{l} \mathrm{EGTA}$, $2 \mathrm{mmol} / 1 \mathrm{Na}_{3} \mathrm{VO}_{4}, 2 \mathrm{mmol} / \mathrm{l} \mathrm{NaF}, 2 \mathrm{mmol} / 1 \mathrm{Na}_{4} \mathrm{P}_{2} \mathrm{O}_{7}$, $1 \mathrm{mmol} / \mathrm{l}$ phenylmethylsulfonylfluoride (PMSF), $20 \mu \mathrm{g} / \mathrm{ml}$ leupeptin, $10 \mu \mathrm{g} / \mathrm{ml}$ aprotinin and $1 \mu \mathrm{mol} / 1 \mathrm{LR}$-microcystin, as described $[18,20]$. Muscle homogenates were supplemented with $150 \mathrm{mmol} / 1 \mathrm{NaCl}, 1 \%$ Triton X-100 and $0.5 \%$ Nonidet, and equal amounts of lysate were protein-immunoprecipitated at $4{ }^{\circ} \mathrm{C}$ with antisera for determination of aPKC activity, and activity and phosphorylation of PKB $\alpha$ or $\operatorname{PKB} \beta$. Precipitates were collected on Sepharose-AG beads (Santa Cruz Biotechnology, Santa Cruz, CA, USA) and assayed as described below.

For each assay, as alluded to above, muscle samples of several non-diabetic and diabetic patients, studied basally and at submaximal or maximal insulin concentrations, were simultaneously homogenised, immunoprecipitated and assayed (in replicate immunoprecipitates) to provide intraassay side-by-side comparisons. This approach was used to avoid any differences in sample handling and assay.

aPKC activation aPKC activity was measured as described previously $[18,20]$. In brief, aPKCs were immunoprecipitated with a rabbit polyclonal antiserum (Santa Cruz Biotechnology) that recognises a common epitope in the C-termini of $\mathrm{PKC} \zeta$ and $\mathrm{PKC} \lambda / \mathrm{l}$, collected on SepharoseAG beads, and incubated for $8 \mathrm{~min}$ at $30^{\circ} \mathrm{C}$ in $100 \mu \mathrm{l}$ buffer containing $50 \mathrm{mmol} / 1 \mathrm{Tris} / \mathrm{HCl}(\mathrm{pH}, 7.5), 100 \mu \mathrm{mol} / 1$
$\mathrm{Na}_{3} \mathrm{VO}_{4}, 100 \mu \mathrm{mol} / 1 \mathrm{Na}_{4} \mathrm{P}_{2} \mathrm{O}_{7}, 1 \mathrm{mmol} / \mathrm{l} \mathrm{NaF}, 100 \mu \mathrm{mol} / \mathrm{l}$ PMSF, $4 \mu \mathrm{g}$ phosphatidylserine (Sigma, St Louis, MO, USA), $50 \mu \mathrm{mol} / 1\left[\gamma_{-}{ }^{32} \mathrm{P}\right] \mathrm{ATP}$ (NEN/Life Science Products, Boston, MA, USA), $5 \mathrm{mmol} / 1 \mathrm{MgCl}_{2}$ and, as substrate, $40 \mu \mathrm{mol} / 1$ serine analogue of the PKC- $\varepsilon$ pseudosubstrate (BioSource, Camarillo, CA, USA). After incubation, ${ }^{32} \mathrm{P}$-labelled substrate was trapped on P-81 filter paper and counted in a liquid scintillation counter.

PKB activation PKB activation was assessed by western blotting analysis and immunoblotting for phosphorylation of threonine (Thr)-308 and serine (Ser)-473 residues in $\mathrm{PKB}$, as described $[18,20]$; these residues are rapidly phosphorylated in response to acute insulin treatment. Western analyses were conducted with whole-cell muscle lysates or with immunoprecipitates of $\mathrm{PKB} \alpha$ or $\mathrm{PKB} \beta$. $\mathrm{PKB} \alpha$ was immunoprecipitated with mouse monoclonal antibody (Upstate Cell Signaling Technology, Lake Placid, NY, USA). PKB $\beta$ was immunoprecipitated with rabbit polyclonal antiserum (Upstate Cell Signaling Technology) or mouse monoclonal antibody (Santa Cruz Biotechnology). In these analyses, each diabetic subject was compared with at least three non-diabetic control subjects (from which a mean difference was determined) to be certain that observed differences reflected true deviations from the non-diabetic control group rather than random variations.

We also measured enzymatic activities of immunoprecipitable $\mathrm{PKB} \alpha$ and $\mathrm{PKB} \beta$ using antibodies described above and assay reagents supplied by Upstate Cell Signaling Technology, as described [18, 20].

Western blotting analyses As described [18, 20], muscle lysates were immunoblotted for $\mathrm{PKC} \zeta / \lambda$ (Santa Cruz Biotechnology; a C-terminal rabbit polyclonal antiserum that recognises aPKCs $\zeta$ and $\lambda$ ), phospho-Ser-473-PKB (rabbit polyclonal antiserum or mouse monoclonal antibody from Upstate Cell Signaling Technology), phospho-Thr308-PKB (rabbit polyclonal antiserum from Upstate Cell Signaling Technology), $\mathrm{PKB} \alpha / \beta$ (goat polyclonal antiserum from Santa Cruz Biotechnology) and phospho-Thr-410PKC $\zeta$ (mouse monoclonal antibody from Cell Signaling, Beverly, MA, USA). Samples from non-diabetic and diabetic subjects were blotted simultaneously, and the resulting extended chemiluminescence (ECL) was quantified by laser scanning densitometry and expressed as relative values.

Blood/plasma analyses Levels of $\mathrm{HbA}_{1 \mathrm{c}}$, fasting glucose, immunoreactive insulin, C-peptide and triacylglycerol were determined as described $[18,20]$.

Statistical methods Data are reported as actual cpm for each immunoprecipitate observed in aPKC and $\mathrm{PKB} \alpha$ assays, 
and as relative values when comparing results of immunoblots. Data are expressed as means \pm SEM. Statistical differences between two means (as in Table 1) were determined by Student's unpaired $t$ test and those between three or more groups (as in Figs. 1 and 2) were determined by one-way ANOVA using the least significant multiple comparison method.

\section{Results}

Subject characteristics Clinical characteristics and laboratory data on non-diabetic and diabetic subjects are summarised in Table 1. BMI was increased $(p<0.01)$ in diabetic subjects, as was fasting plasma glucose $(p<0.005), \mathrm{HbA}_{1 \mathrm{c}}(p<0.05)$ and fasting serum insulin concentration $(p<0.05)$. Fasting triacylglycerol concentration trended upwards in diabetic subjects, but not significantly. Maximal insulin-stimulated glucose disposal rates were diminished in diabetic subjects $(p<0.001)$.

aPKC activation In non-diabetic subjects, muscle aPKC activity increased stepwise approximately twofold and threefold, as the serum insulin concentration was increased from a basal value of $55 \pm 11 \mathrm{pmol} / 1$ to an intermediate submaximal level of $450 \pm 83 \mathrm{pmol} / 1$ and to a higher maximally effective level of $1,406 \pm 172 \mathrm{pmol} / \mathrm{l}$, respectively, during the clamp procedures (Fig. 1a). In diabetic subjects, muscle aPKC activity prior to insulin administration was, if anything, slightly, but not significantly, less than that found in non-diabetic subjects (Fig. 1a). More importantly, insulin-stimulated aPKC activity in diabetic muscle increased only slightly, if at all, as the serum insulin concentration was increased from a basal level of $111 \pm 28$ to an intermediate submaximal level of $490 \pm 60 \mathrm{pmol} / \mathrm{l}$, and only modestly at the higher maximally effective insulin concentration of $1400 \pm 100 \mathrm{pmol} / \mathrm{l}$ (Fig. 1a). Defects in

Table 1 Clinical characteristics of diabetic and non-diabetic subjects

\begin{tabular}{lll}
\hline & $\begin{array}{l}\text { Non-diabetic } \\
\text { subjects } \\
(n=8)\end{array}$ & $\begin{array}{l}\text { Diabetic } \\
\text { subjects } \\
(n=7)\end{array}$ \\
\hline Age (years) & $45 \pm 2$ & $51 \pm 3$ \\
BMI & $27 \pm 1$ & $34 \pm 2$ \\
Fasting plasma glucose (mmol/1) & $5.2 \pm 0.2$ & $11.3 \pm 1.7$ \\
HbA $_{1 \mathrm{c}}(\%)$ & $5.6 \pm 0.1$ & $7.7 \pm 0.9$ \\
Serum insulin (pmol/l) & $54 \pm 8$ & $106 \pm 20$ \\
Serum triacylglycerol (mol/1) & $1.02 \pm 0.13$ & $2.97 \pm 1.60$ \\
Maximal glucose disposal rate $_{\left(\mathrm{nmol} \mathrm{kg} \text { min }^{-1} \text { ) }\right.}^{70 \pm 7.6}$ & $28 \pm 5.9$ \\
\hline
\end{tabular}

aPKC activation in diabetic muscle were significant at both submaximal and maximal insulin levels (Fig. 1a).

Although not depicted here, the degree of activation of muscle aPKC, the degrees of both activation and phosphorylation of PKB, and the increases in insulinstimulated glucose disposal in non-diabetic and diabetic subjects observed at a serum insulin concentration of $1,400 \mathrm{pmol} / 1$ were comparable to (i.e. as great or greater than) those observed previously with higher serum insulin concentrations (approximately 4,000-6,000 pmol/1) [18, 20]. In addition, four control and four diabetic subjects studied in the present work were subjected to clamp procedures in which serum insulin concentrations of approximately 2,500 pmol/1 were attained, and their glucose disposal rates and levels of muscle aPKC activation and PKB activation and phosphorylation were similar to those observed at $1,400 \mathrm{pmol} / \mathrm{l}$. Thus, the higher concentration of insulin we used in the clamp procedure (approximately $1,400 \mathrm{pmol} / \mathrm{l}$ ) in the present study provoked maximal or near-maximal insulin effects on aPKC and PKB in muscle.

Unlike the phosphorylation of PKB (see below), the phosphorylation of threonine-410 in the aPKC activation loop (measured in aPKC immunoprecipitates) was not influenced by insulin treatment or the presence of diabetes in our clamp studies (Fig. 2a). It therefore appears that this phosphorylation, while required, is for the most part constitutive and is not an effective measure of aPKC activation, and, moreover, is not compromised in diabetic muscle. Also note that the recovery of immunoprecipitated aPKC was not influenced by the concentration of insulin, and was comparable in diabetic and non-diabetic subjects (Fig. 2a) despite the fact that aPKC levels are moderately diminished in lysates of diabetic muscle [18].

Glucose dispersal rates In association with concentration-related increases in insulin-induced muscle aPKC activity in non-diabetic subjects, there were similar relative increases in insulin-stimulated whole-body glucose disposal rates as serum insulin was increased from basal to submaximal and maximally effective levels (Fig. 1b). Comparable to the poor insulin-induced increases in muscle aPKC activation in diabetic subjects, insulin-stimulated glucose disposal rates were diminished in diabetic subjects both at submaximal and maximal insulin concentrations (Fig. 1b). Note that glucose disposal rates at submaximal insulin levels were approximately $40-50 \%$ of those observed at maximal insulin levels in both non-diabetic and diabetic subjects (Fig. 1b). Thus, the present studies with submaximal insulin concentrations reflected conditions of approximately half-maximal insulin stimulation, at least with respect to overall glucose utilisation. 
Fig. 1 Effects of stimulation with submaximal and maximally effective insulin levels on enzyme activities of muscle aPKC (a), $\operatorname{PKB} \alpha(\mathbf{c})$ and $\operatorname{PKB} \beta$ (d) and glucose disposal rates (b) in non-diabetic (open bars) and diabetic (shaded bars) subjects. Values are means \pm SEM of five to seven determinations. Note that basal values of the two clamp studies conducted in each subject were similar and have therefore been combined.

Symbols indicate significant differences between diabetic and non-diabetic subjects $\left({ }^{*} p<0.05\right.$, $* * p<0.01)$ and between basal and insulin-stimulated subjects $\left({ }^{\pi} p<0.05 ;{ }^{\top \pi} p<0.01\right.$, ${ }^{419} p<0.001$ ) (ANOVA). Unless indicated otherwise, differences between diabetic and nondiabetic subjects were not significant

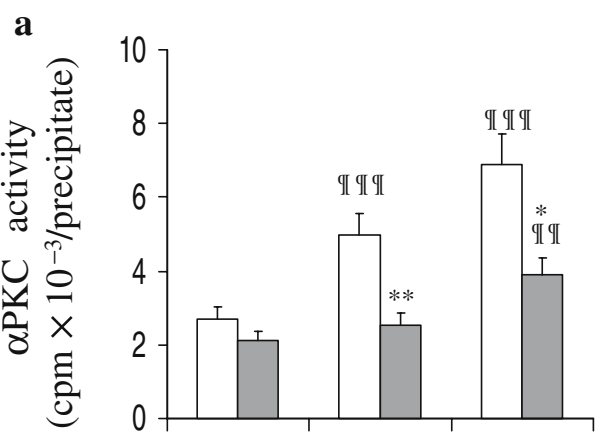

Insulin: Basal Sub- Maximal

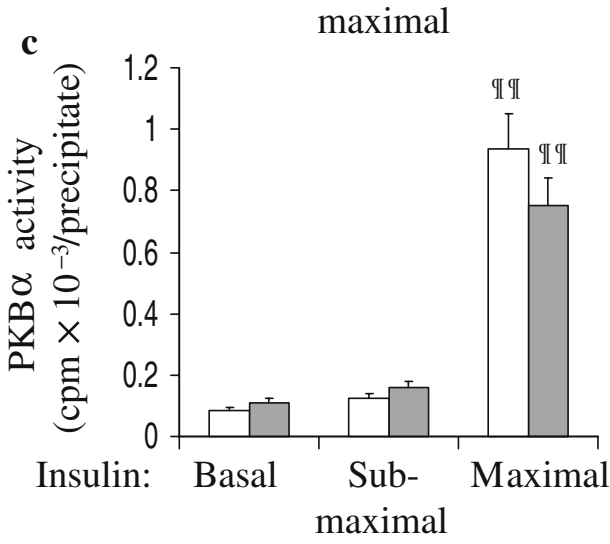

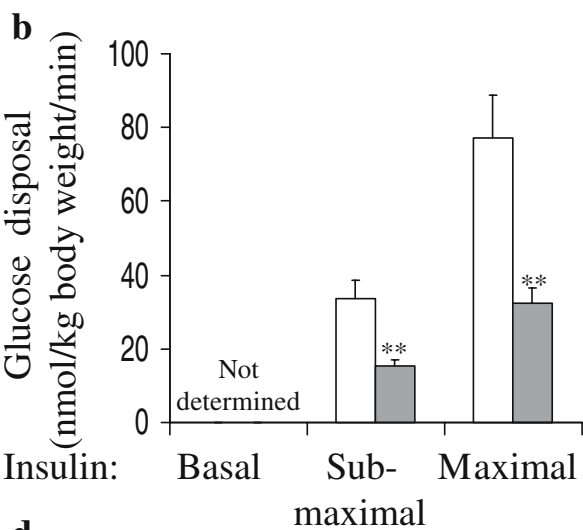

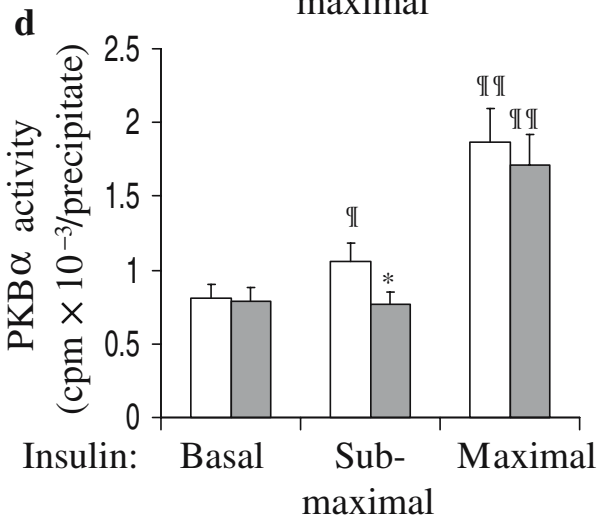

$P K B$ enzyme activation In muscles of non-diabetic subjects, the higher maximal insulin concentration provoked sizeable increases in enzyme activities of both $\operatorname{PKB} \alpha$ and $\mathrm{PKB} \beta$ (Fig. 1c and d). On the other hand, the submaximal concentration of insulin elicited a modest but significant $25 \%$ increase in enzyme activity of PKB $\beta$ (Fig. 1d), but $\operatorname{PKB} \alpha$ enzyme activity was not significantly increased in muscles of non-diabetic subjects (Fig. 1c). The failure to observe a significant increase in $\mathrm{PKB} \alpha$ activity at submaximal insulin concentration may be due to high variable basal values and a relatively low level of activation, i.e. a relatively poor signal-to-noise ratio; it is also possible that a more sizeable but transient increase in $\operatorname{PKB} \alpha$ activity may have been apparent at earlier times of submaximal insulin treatment.

As reported previously [18-20], in studies using maximal insulin stimulation the increases in $\operatorname{PKB} \alpha$ activity were mildly, but not significantly, lower in diabetic than in nondiabetic muscle (Fig. 1c). Similarly, the activation of PKB $\beta$ appeared to be largely intact in diabetic muscle studied at maximal insulin stimulation (Fig. 1d). In contrast to the modest but significant activation of $\mathrm{PKB} \beta$ in non-diabetic muscle, there was no appreciable activation of $\mathrm{PKB} \beta$ in diabetic muscle stimulated by the submaximal insulin level used in the present study (Fig. 1d).

PKB phosphorylation We also examined changes in phosphorylation of (1) Thr-308 in the activation loop of PKB, which is dependent upon 3-phosphoinositide-dependent protein kinase-1 (PDK1) and PI3K-dependent increases in phosphatidylinositol-3,4,5-trisphosphate (PIP3), which binds to PKB and facilitates PDK1 action; and (2) Ser473 , which is phosphorylated by a putative 3-phosphoinositide-dependent protein kinase-2 (PDK2) and probably requires prior phosphorylation of Thr-308 by PDK1.

In muscles of non-diabetic subjects, unlike enzymatic activation, the phosphorylation of both Thr-308 and Ser473 residues in total PKB was increased near-maximally at the lower submaximal insulin concentration and, on average, further increases (if any) were only modest in response to maximal insulin stimulation (Fig. 2a,c and e).

In muscles of diabetic subjects stimulated maximally by insulin, similar to changes in $\operatorname{PKB} \alpha$ and $\mathrm{PKB} \beta$ enzyme activities (cf. Fig. 1c), the phosphorylation of Thr-308 and Ser-473 in total PKB was not significantly diminished relative to non-diabetic subjects (Fig. 2a,c and e). On the other hand, phosphorylation of both Thr-308 and Ser-473 in total PKB was significantly impaired in diabetic muscle stimulated by the lower submaximal insulin concentration (Fig. 2a,c and e).

In addition to total $\mathrm{PKB}$, we examined the phosphorylation of $\mathrm{PKB} \alpha$ and $\mathrm{PKB} \beta$, as precipitated by isoformselective antibodies. In non-diabetic subjects, as with total PKB, phosphorylation of Thr-308 and Ser-473 in PKB $\alpha$ and $\mathrm{PKB} \beta$ was near-maximal at the lower submaximal insulin concentration (Fig. 2a,b,d,f and g). In diabetic subjects, as with total PKB, phosphorylation of Thr-308 
a
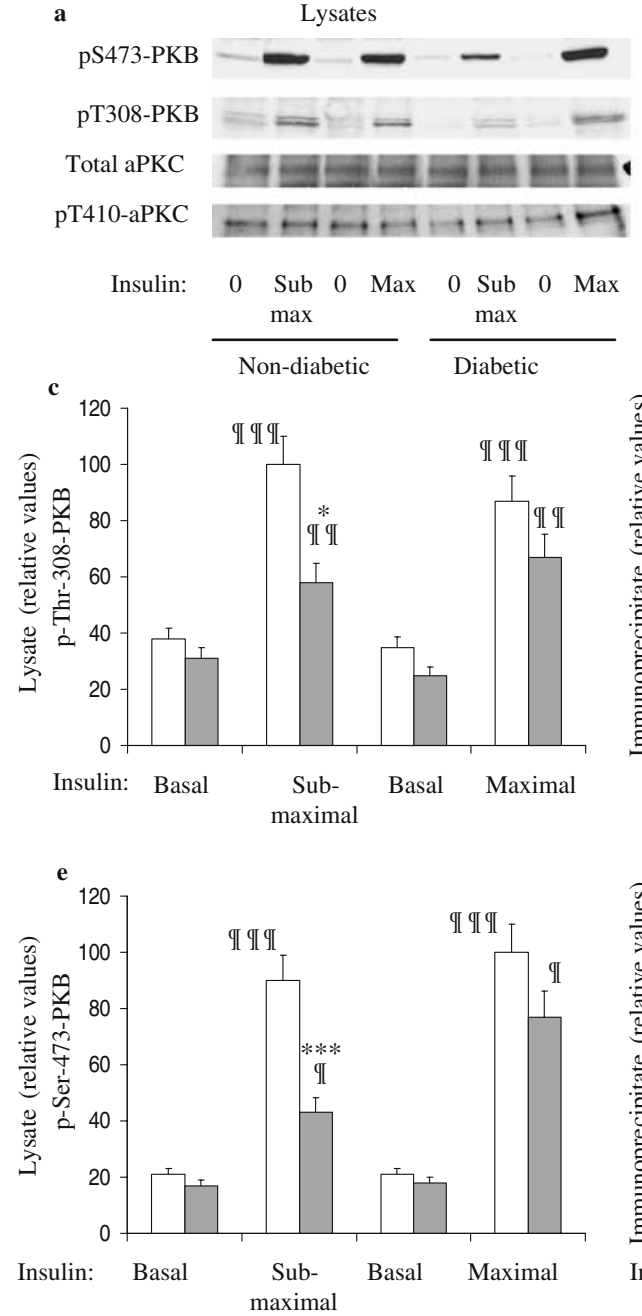

b

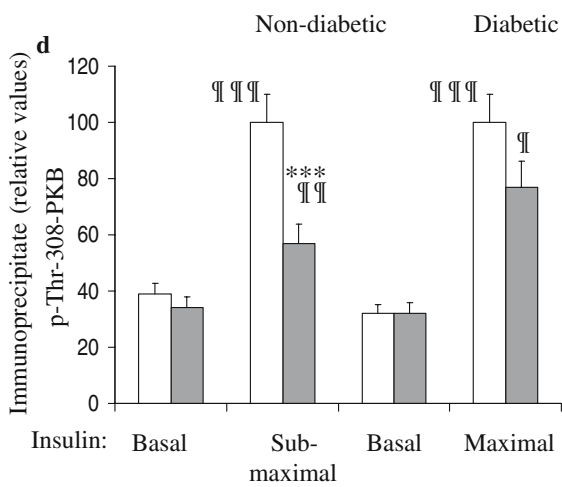

PKB Immunoprecipitates
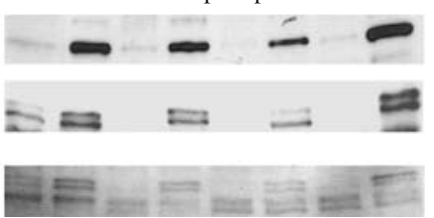

PKB Immunoprecipitates
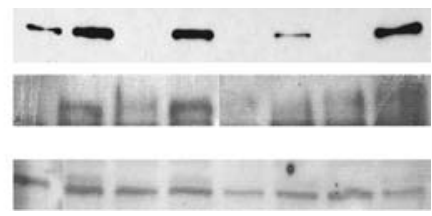

$\begin{array}{llllllll}0 & \text { Sub } & 0 & \text { Max } & 0 & \text { Sub } & 0 & \text { Max }\end{array}$

$\frac{\max }{\text { Non-diabetic }} \frac{\max }{\text { Diabetic }}$

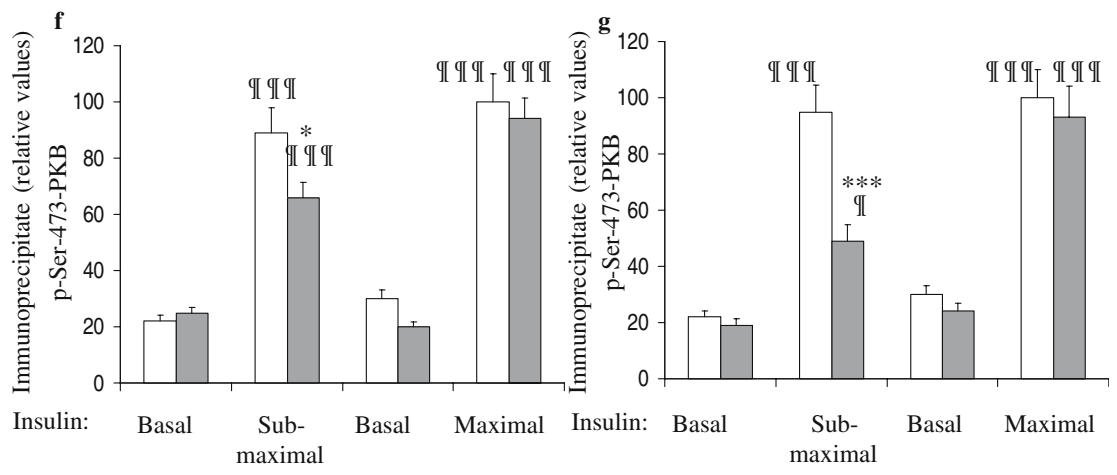

Fig. 2 Phosphorylation of phospho(p)-threonine(T)-308 and phospho (p)-serine(S)-473 in PKB as determined in whole lysates (a, c, e), and in immunoprecipitates $(\mathbf{b}, \mathbf{d}, \mathbf{f}, \mathbf{g})$ of $\operatorname{PKB} \alpha(\mathbf{b}, \mathbf{d}, \mathbf{f})$ and $\operatorname{PKB} \beta(\mathbf{b}, \mathbf{g})$ obtained from muscles of non-diabetic (open bars) and diabetic (shaded bars) subjects subjected to insulin stimulation by submaximal and maximal insulin concentrations during the clamp procedure. In $\mathbf{b}$, $\mathbf{d}$ and $\mathbf{f}, \mathrm{PKB} \alpha$ was immunoprecipitated with mouse monoclonal anti$\mathrm{PKB} \alpha$ antibody and blotted with rabbit polyclonal anti-p-T-308-PKB or anti-S-473-PKB antiserum. In $\mathbf{b}$ and $\mathbf{g}, \mathrm{PKB} \beta$ was precipitated with rabbit polyclonal anti-PKB $\beta$ antiserum and blotted with mouse monoclonal anti-p-S-473-PKB antibody. (Because of high background and a strong non-specific adjacent band, it was not possible to obtain reliable quantitative data from $\mathrm{p}$-T-308-PKB blots of

PKB $\beta$ immunoprecipitates.) Basal indicates values obtained prior to insulin administration in the clamp procedure. Representative blots are shown in $\mathbf{a}$ and $\mathbf{b}$. Values in $\mathbf{c}-\mathbf{g}$ reflect means \pm SEM of five to seven determinations of values expressed relative to the mean maximal insulin level, set at 100. Symbols indicate significant differences between diabetic and non-diabetic subjects $(* p<0.05, * * * p<0.001)$ and between basal and insulin-stimulated subjects/conditions $\left(p<0.05\right.$, or $\left.{ }^{\uparrow} p<0.01,{ }^{\uparrow \uparrow} p<0.001\right)$ (ANOVA). Unless indicated otherwise, differences between diabetic and non-diabetic subjects were not significant. Also shown in a is a representative blot showing that levels of total aPKC and p-T-410-aPKC were comparable in immunoprecipitates obtained from diabetic and non-diabetic subjects, and were not influenced by insulin treatment

and Ser-473 in $\mathrm{PKB} \alpha$ and $\mathrm{PKB} \beta$ was diminished at the lower submaximal, but not at the higher maximal, insulin level (Fig. 2a,b,d,f and g).

\section{Discussion}

zBy examining signalling at submaximal and maximal insulin levels, we were able to observe significant defects in

both PKB activation/phosphorylation and aPKC activation in muscles of obese diabetic humans. Defects in muscle PKB activation/phosphorylation in obese diabetic subjects were readily apparent at submaximal insulin concentrations, but, in contrast, were smaller and not statistically significant at maximally effective insulin levels. Thus, previous failures to observe a significant defect in insulin-stimulated PKB phosphorylation and/or activation in human diabetic muscle in clamp studies seem to reflect the use of maximally effective insulin levels. 
The finding of a defect in PKB activation/phosphorylation in muscles of obese diabetic subjects undergoing clamp procedures on submaximal insulin stimulation is similar to previously reported defects observed in obese non-diabetic subjects [24] and non-obese diabetic subjects [25]. However, only one submaximal insulin concentration was used in the previous studies, and it is uncertain whether defects in PKB phosphorylation would have been evident at higher insulin levels. In any case, significant defects in PKB phosphorylation and enzymatic activation were not evident either in the present studies or in several previously reported studies of obese non-diabetic [19, 20], obese glucose-intolerant [18] and obese diabetic $[19,20]$ subjects studied at higher insulin levels.

A caveat arising in the present study that may be relevant to previous studies of muscle PKB enzyme activation is that we were able to readily observe insulin-induced increases in $\mathrm{PKB} \alpha$ enzyme activity at the maximally effective insulin concentration but not at the submaximal insulin level in non-diabetic, as well as diabetic, subjects. On the other hand, we were able to discern modest but significant increases in enzyme activity of muscle PKB $\beta$ on submaximal insulin stimulation in non-diabetic, but not diabetic, subjects. It therefore seems clear that the activation of muscle $\mathrm{PKB} \beta$ is impaired in diabetic subjects. This is noteworthy, as the $\mathrm{PKB} \beta$ isoform seems to be particularly important for regulation of glucose metabolism $[14,15]$.

In concert with findings of defective PKB $\beta$ enzyme activation during submaximal insulin stimulation in diabetic muscle, the phosphorylation of Thr-308 and Ser-473 residues of total $\mathrm{PKB}$ and both $\mathrm{PKB} \alpha$ and $\mathrm{PKB} \beta$ isoforms was impaired during submaximal insulin stimulation. This provided further evidence that PKB activation is defective in diabetic muscle, and also verified that the defect in PKB activation involved alterations in PDK1- and PDK2dependent phosphorylation of specific residues required for increases in enzyme activity of both $\mathrm{PKB} \alpha$ and $\mathrm{PKB} \beta$. In this regard, it may be noted that other previously reported clamp studies employing submaximal insulin levels relied upon changes in total PKB phosphorylation, rather than enzyme activity, to detect defects in muscle PKB activation [24, 25].

It was perplexing to find relatively low levels of enzyme activity, despite near-maximal phosphorylation of Thr-308 and Ser-473 residues in PKB, in muscles of non-diabetic subjects studied using submaximal insulin stimulation. This divergence between activity and phosphorylation suggested that poorly understood factors other than phosphorylation of Ser-473 and Thr-308 residues can influence PKB enzyme activity, as measured by the phosphorylation of artificial substrates in PKB immunoprecipitates.

From the above considerations, it may be surmised that the ability to observe defects in insulin-stimulated PKB activation in diabetic subjects is dependent upon the level of insulin stimulation and the parameter of PKB activation under study. Thus, diabetes-dependent defects are best seen at submaximal levels of insulin stimulation, as measured by PKB $\beta$ enzyme activity, or phosphorylation of Thr-308 and Ser-473 residues in total PKB, PKB $\alpha$ and $\mathrm{PKB} \beta$.

The finding that a defect in PKB activation/phosphorylation in diabetic muscle was readily apparent at submaximal, but not maximally effective, insulin levels suggests that this defect is dependent upon impaired activation of an upstream factor(s) present at a level in excess of that needed for full PKB activation/phosphorylation. Upstream activators known to be 'spare' (i.e. to elicit maximal glucose transport responses at relatively low levels of ligand occupancy or activation) include the insulin receptor and factors immediately downstream, most notably, IRS1, which is required for activation of the PI3K responsible for activating PKB and aPKC in muscle [26, 27]. Along these lines, it may further be surmised that, in diabetic muscle (1) at higher levels of insulin stimulation there is only a small or no defect in the ability of PKB to be phosphorylated and enzymatically activated in response to upstream signalling factors; and (2) the defect in PKB activation/phosphorylation observed at lower insulin levels may reflect impaired activation of the insulin receptor, IRS1-dependent PI3K, PDK1 and/or PDK2. In this regard, Kim et al. [19] reported that the activation of PDK1 by insulin is not impaired in diabetic muscle. However, maximally effective insulin levels were used in that clamp study, and from the present findings it may be argued that a defect in PDK1 activation would be apparent only at submaximal insulin levels.

The finding that defects in aPKC activation in diabetic muscle were readily seen at both submaximal and maximal insulin levels implies that, regardless of the degree of saturation of the insulin receptor and activation of spare upstream signalling factors, there is a $\operatorname{defect}(\mathrm{s})$ in a more terminal process, perhaps at or near the level of aPKC. Two known problems in diabetic muscle that could explain such a distal defect in aPKC activation are (1) diminished ability of aPKC to respond to PIP3, as seen in assays of aPKCs immunoprecipitated from muscles of type 2 diabetic humans [18] and monkeys [28], obese humans [20] and monkeys [28], high-fat-fed rodents [29] and cultured myocytes and adipocytes of obese humans [30]; and (2) diminished levels of $\mathrm{PKC} \zeta$, as found in human diabetic muscle $[18,19]$. With respect to the latter possibility, it may be noted that in our assays of aPKC activity comparable amounts of aPKCs are immunoprecipitated [present study; 18, $28]$ and aPKC activities reflect specific activity, i.e. protein kinase activity of a given amount of aPKC. Nevertheless, diminished aPKC levels in diabetic muscle could theoretically limit the ability of aPKC to interact with and be 
activated by upstream activators, viz. IRS1-dependent PI3K, PDK1 and PIP3.

That a significant defect in PKB activation/phosphorylation was seen only at submaximal insulin concentration and therefore appeared to reflect impaired activation of spare upstream signalling factors, rather than a defect in PKB itself, does not diminish the importance of the defect in PKB activation/phosphorylation in contributing to hyperglycaemia in diabetic subjects. Indeed, the levels of serum insulin achieved in submaximal clamp studies are within or close to the high-normal physiological range seen postprandially in lean insulin-sensitive subjects, and clearly within the range seen postprandially in obese insulinresistant subjects. It may therefore be surmised that (1) changes in PKB activation/phosphorylation occur within the range of insulin levels that exist in physiological conditions, viz. approximately 50-500 pmol/1, in lean insulin-sensitive subjects; and (2) defects in muscle PKB activation/phosphorylation seen in the present study at submaximal concentrations of 400-500 pmol/1 contribute importantly to the hyperglycaemia seen in obese diabetic subjects. Only with more marked hyperinsulinaemia in cases of severe insulin resistance would PKB activation/ phosphorylation be expected to be occurring maximally, and therefore presumably normally, in diabetic subjects. In this regard, it may also be surmised that, while defects in insulin-stimulated glucose disposal seen at submaximal insulin concentrations in clamp studies can be attributed to impaired activation of both $\mathrm{PKB}$ and aPKC, defects in glucose disposal seen at maximally effective insulin concentrations may be primarily reflective of impaired aPKC activation.

The present findings emphasise the need to study insulin signalling at submaximal (preferably approximating halfmaximal for glucose disposal) and maximal levels in order (1) to evaluate more fully the question of the existence or non-existence of defects in insulin signalling factors; and (2) gain a more complete picture of what signalling defects may be related to abnormalities in metabolic processes in insulin-resistant states.

Acknowledgements This work was supported by funds from the Department of Veterans Affairs Merit Review Program and National Institutes of Health Research Grant 2RO1-DK-38079.

\section{References}

1. Bandyopadhyay G, Standaert ML, Zhao L et al (1997) Activation of protein kinase $\mathrm{C}(\alpha, \beta$, and $\zeta)$ by insulin in 3T3/11 cells. Transfection studies suggest a role for $\mathrm{PKC}-\zeta$ in glucose transport. J Biol Chem 272:2551-2558

2. Standaert ML, Galloway L, Karnam P, Bandyopadhyay G, Moscat J, Farese RV (1997) Protein kinase C- $\zeta$ as a downstream effector of phosphatidylinositol 3-kinase during insulin stimulation in rat adipocytes. Potential role in glucose transport. J Biol Chem 272:30075-30082

3. Kotani K, Ogawa W, Matsumoto M et al (1998) Requirement of atypical protein kinase $\mathrm{C} \lambda$ for insulin stimulation of glucose uptake but not for Akt activation in 3T3/11 adipocytes. Mol Cell Biol 18:6971-6982

4. Bandyopadhyay G, Kanoh Y, Sajan MP, Standaert ML, Farese RV (2000) Effects of adenoviral gene transfer of wild-type, constitutively active, and kinase-defective protein kinase $\mathrm{C}-\lambda$ on insulinstimulated glucose transport in L6 myotubes. Endocrinology 141:4120-4127

5. Bandyopadhyay G, Sajan MP, Kanoh Y et al (2002) PKC- $\zeta$ mediates insulin effects on glucose transport in cultured preadipocyte-derived human adipocytes. J Clin Endocrinol Metab $87: 716-726$

6. Condorelli G, Vigliotta G, Trencia A et al (2001) Protein kinase C (PKC) $-\alpha$ activation inhibits $\mathrm{PKC}-\zeta$ and mediates the action of PED/PEA-15 on glucose transport in L6 muscle cells. Diabetes 50:1244-1250

7. Bandyopadhyay G, Standaert ML, Sajan MP et al (2004) Protein kinase $\mathrm{C}-\lambda$ knockout in embryonic stem cells and adipocytes impairs insulin-stimulated glucose transport. Mol Endocrinol $18: 373-383$

8. Ugi S, Imamura T, Maegawa $\mathrm{H}$ et al (2004) Protein phosphatase 2A negatively regulates insulin's metabolic pathway by inhibiting Akt (protein kinase B) activity in 3T3/11 adipocytes. Mol Cell Biol 24:8778-87789

9. Canto C, Suarex E, Lizcano JM et al (2004) Neuroregulin signaling on glucose transport in muscle cells. J Biol Chem 279: $12260-12268$

10. Arribas M, Valverde AM, Burks D et al (2003) Essential role of protein kinase Czeta in the impairment of insulin-induced glucose transport in IRS-2-deficient brown adipocytes. FEBS Lett 536:161-166

11. Kohn AD, Summers SA, Birnbaum MJ, Roth RA (1996) Expression of a constitutively active Akt Ser/Thr kinase in 3T3/ 11 adipocytes stimulates glucose uptake and glucose transporter 4 translocation. J Biol Chem 271:31372-31378

12. Tanti J, Grillo S, Gremeaux T, Coffer PJ, Van Obberghen E, Le Marchand-Brustel Y (1997) Potential role of protein kinase B in glucose transporter 4 translocation in adipocytes. Endocrinology 138:2005-2009

13. Wang Q, Somwar R, Bilan PJ et al (1999) Protein kinase B/Akt participates in GLUT4 translocation in L6 myoblasts. Mol Cell Biol 19:4008-4018

14. Hill MM, Clark SF, Tucker DF, Birnbaum MJ, James DE, Macaulay SL (1999) A role for protein kinase Bß/Akt2 in GLUT4 translocation in adipocytes. Mol Cell Biol 19:77717781

15. Bae SS, Cho H, Mu J, Birnbaum MJ (2003) Isoform-specific regulation of insulin-dependent glucose uptake by Akt/protein kinase B. J Biol Chem 278:49530-49536

16. Goodyear LJ, Giorgino F, Sherman LA, Smith RJ, Dohm GL (1995) Insulin receptor phosphorylation, IRS-1 phosphorylation, and phosphatidylinositol 3-kinase activity are decreased in intact skeletal muscle from obese subjects. J Clin Invest 95:2195-2204

17. Bjornholm M, Kawano Y, Lehtihet M, Zierath JR (1997) Insulin receptor substrate-1 phosphorylation and phosphatidylinositol 3-kinase activity in skeletal muscle from NIDDM subjects after in vivo insulin stimulation. Diabetes 46:524-527

18. Beeson M, Sajan MP, Dizon M et al (2003) Activation of protein kinase $\mathrm{C}-\zeta$ by insulin and phosphatidylinositol-3,4,5-( $\left(\mathrm{PO}_{4}\right)_{3}$ is defective in muscle in type 2 diabetes and impaired glucose tolerance: amelioration by rosiglitazone and exercise. Diabetes 52:1926-1934 
19. Kim Y-B, Kotani K, Ciaraldi TP, Henry RR, Kahn BB (2003) Insulin-stimulated $\mathrm{PKC}-\lambda / \zeta$ activity is reduced and PDK- 1 activity is normal in muscle of insulin resistant humans. Diabetes 52:1935-1942

20. Beeson M, Sajan MP, Gomez-Daspet J et al (2003) Defective activation of protein kinase $\mathrm{C}-\zeta$ in muscle by insulin and phosphatidylinositol-3,4,5-( $\left.\mathrm{PO}_{4}\right)_{3}$ in obesity and polycystic ovary syndrome. Metab Syndrome Relat Disord 2:49-55

21. Kim Y-B, Nikoulina SE, Ciaraldi TP, Henry RR, Kahn BB (1999) Normal insulin-dependent activation of Akt/protein kinase B, with diminished activation of phosphoinositide 3-kinase in muscle in type 2 diabetes. J Clin Invest 104:733-741

22. Brozinick JT, Roberts BR, Dohm DL (2003) Defective signaling through Akt-2 and -3 but not Akt-1 in insulin-resistant skeletal muscle. Diabetes 52:935-941

23. Krook A, Roth RA, Jiang XJ, Zierath JR, Wallberg-Henriksson H (1998) Insulin-stimulated Akt activity is reduced in skeletal muscle from NIDDM subjects. Diabetes 47:1281-1286

24. Adams JM II, Pradipanawar T, Berria R et al (2004) Ceramide content is increased in skeletal muscle from obese insulin-resistant humans. Diabetes 53:25-31

25. Karlsson HKR, Zierath J, Kane S, Krook A, Lienhard GE, Wallberg-Henriksson H (2005) Insulin-stimulated phosphorylation of the Akt substrate AS160 is impaired in skeletal muscle of type 2 diabetic subjects. Diabetes 54:1692-1697

26. Yamauchi T, Tobe K, Tamemoto $H$ et al (1996) Insulin signalling and insulin actions in the muscles and livers of insulin-resistant, insulin receptor substrate 1-deficient mice. Mol Cell Biol 16:3074-3084

27. Sajan MP, Standaert ML, Miura A, Kahn CR, Farese RV (2004) Tissue-specific differences in activation of atypical protein kinase $\mathrm{C}$ and protein kinase $\mathrm{B}$ in muscle, liver, and adipocytes of insulin receptor substrate-1 knockout mice. Mol Endocrinol 18:2513-2521

28. Standaert ML, Ortmeyer HK, Sajan MP et al (2002) Skeletal muscle insulin resistance in obesity-associated type 2 diabetes mellitus in monkeys is linked to a defect in insulin activation of protein kinase C- $\zeta / \lambda / \lambda$. Diabetes 51:2936-2943

29. Kanoh Y, Sajan MP, Bandyopadhyay G, Miura A, Standaert ML, Farese RV (2003) Defective activation of protein kinase $C \zeta$ and $\lambda$ by insulin and phosphatidylinositol-3,4,5,-( $\left(\mathrm{PO}_{4}\right)_{3}$ in skeletal muscle of rats following high-fat feeding and streptozotocininduced diabetes. Endocrinology 144:947-954

30. Sajan MP, Standaert ML, Miura A et al (2004) Impaired activation of protein kinase $\mathrm{C} \zeta$ and $\lambda$ by insulin and phosphatidylinositol$3,4,5,-\left(\mathrm{PO}_{4}\right)_{3}$ in cultured pre-adipocytes and myotubes of obese subjects. J Clin Endocrinol Metab 89:3994-3998 